\section{The Drosophila MSL complex activates the transcription of target genes}

\author{
Tobias Straub, ${ }^{1}$ Gregor D. Gilfillan, ${ }^{1}$ \\ Verena K. Maier, and Peter B. Becker ${ }^{2}$ \\ Adolf Butenandt-Institute, Molecular Biology Unit, \\ Ludwig-Maximilians-University, 80336 Munich, Germany
}

The mechanism through which gene expression originating from the single male or the two female $X$ chromosomes in Drosophila is adjusted to autosomal gene expression has remained controversial. According to the prevalent model, transcription of the male $X$ is increased twofold by the male-specific-lethal (MSL) complex. However, a significant body of data supports an alternative model, whereby compensation involves a global repression of autosomal gene expression in males by sequestration and neutralization of an activator onto the $X$ chromosome. In order to rigorously discriminate between these models we identified direct target genes for the MSL complex and quantified transcription in absolute terms after knockdown of MSL2. The results unequivocally document an approximate twofold activation of target genes by the MSL complex.

Supplemental material is available at http://www.genesdev.org.

Received June 10, 2005; revised version accepted August 2, 2005.

In Drosophila, male cells contain only a single copy of the $\mathrm{X}$ chromosome, whereas female cells harbor two $\mathrm{X}$ chromosomes. The different dosage of X-linked genes in males versus females necessitates a compensatory adjustment of gene expression. The mechanism through which dosage compensation is achieved is still a matter of debate. As proposed by the prevailing model, a malespecific regulatory complex of proteins and noncoding RNA, the male-specific-lethal (MSL) complex, functions as an activator that doubles the transcription of X-linked target genes in males (for review see, Gorman and Baker 1994; Kelley and Kuroda 1995; Lucchesi 1998; Straub et al. 2005a). The strongest argument for this model, which we refer to as the "activation model" was the finding that all components of the complex (MSL1-3, MLE, the histone acetyl transferase MOF (males absent on the first), the noncoding RNAs roX1, and roX2) and the acetylation of Lys 16 of histone $\mathrm{H} 4$ (H4K16ac) are specifically enriched on the male X (Kuroda et al. 1991; Palmer et al. 1993; Bashaw and Baker 1995; Gorman et al. 1995; Kelley et al. 1995; Zhou et al. 1995; Gu et al. 1998; Franke and Baker 1999|. In selected cases, the MSL

[Keywords: Dosage compensation; transcription; MSL complex]

${ }^{1}$ These authors contributed equally to this work.

${ }^{2}$ Corresponding author.

E-MAIL pbecker@med.uni-muenchen.de; FAX 49-89-2180-75425.

Article and publication are at http://www.genesdev.org/cgi/doi/10.1101/ gad. 1343105 complex has been mapped to the coding regions of active genes (Sass et al. 2003). Furthermore, acetylation of K16 on histone $\mathrm{H} 4$ can lead to strong de-repression of transcription (Akhtar and Becker 2000). Thus, it has been proposed that the twofold increase in transcription is directly due to a change of chromatin structure caused by local or domain-wide histone hyperacetylation. However, it has never been demonstrated unequivocally in vivo that binding of the complex to a specific gene is directly related to its hyperactivation.

To the contrary, the activation model has been challenged over the years, most prominently by Birchler et al. (for review, see Birchler et al. 2003; Straub et al. 2005a). They argue that due to a phenomenon called the "inverse dosage effect," the X-chromosomal monosomy in males leads to global activation of all chromosomes. According to their model, which we shall term the "inverse model," the MSL complex evolved to counteract the inverse dosage effect on autosomal gene expression. The inverse dosage effect summarizes a multitude of observations in many organisms, where aneuploid states lead to global changes in gene expression (Birchler et al. 2001, 2005). Generally, deletions of large chromosomal regions frequently result in a modest (twofold) activation of the remaining genome, whereas duplications of chromosomal segments are associated with a corresponding reduction of overall transcription. Although the molecular basis for the inverse dosage effect is presently unclear, one may imagine that the global expression of a genome is negotiated by a balance between rather general activators and repressors that function through changing the properties of chromatin. Assuming a prevalence of genes encoding general negative effectors of transcription (these may include all constituents of chromatin) over genes that that encode global activators, any loss of a larger piece of the genome is likely to remove more repressive than activating genes, leading to a genome-wide elevation of transcription.

The inverse model for dosage compensation in Drosophila assumes that the MSL complex serves to counteract the global activation of the genome that follows $\mathrm{X}$ monosomy by sequestrating a global activator (conceivably MOF) to the $\mathrm{X}$, thus down-regulating and thereby readjusting autosomal transcription. In this scenario the MSL complex has repressive properties that neutralizes the concentration of activator on the $\mathrm{X}$ thereby preventing its hyperactivation. A crucial distinction of the inverse model from the activation model is, therefore, that the MSL complex is a repressor in the former model and its interaction with the $\mathrm{X}$ chromosome does not correlate with activation of X-linked genes.

Measuring relative changes of X-chromosomal to autosomal gene expression upon disruption of MSL complex (Belote and Lucchesi 1980; Chiang and Kurnit 2003) did not clarify the validity of either of the two models. A priori, such analyses fail to disclose whether such changes are due to reduced X-chromosomal expression (supporting the activation model) or to an increase in autosomal expression caused by the "release" of a global activator (supporting the inverse model). Therefore, absolute measurements of changes in gene expression have been performed by Birchler and colleagues (Hiebert and Birchler 1994; Bhadra et al. 1999, 2000; Pal Bhadra et al. 2005). The results obtained rather supported the idea of 
compensation being based on an inverse dosage effect, as they revealed an up-regulation of a number of autosomal genes upon MSL complex disruption with expression of X-linked genes remaining largely unchanged. However, several caveats prevented widespread acceptance of the inverse model (Straub et al. 2005a). First, measurements were performed in MSL mutant embryos or larvae that are bound to die. Hence, the observed gene expression changes may be due to deregulation preceding lethality. Furthermore, absolute measurements in the mutants revealed heterogeneous, gene-specific responses rather than uniform effects as implicated by a global inverse dosage effect underlying the whole process. Finally, since interaction of the MSL complex with the $\mathrm{X}$ is not a uniform coating (Demakova et al. 2003), it remained unclear which of the observed effects were due to a direct action of the complex.

We carefully re-evaluated the proposed mechanisms of dosage compensation and improved previous analysis procedures by several means: First, we mapped MSL complex binding to specific genes on the male $\mathrm{X}$ chromosome in vivo. Second, we employed a model system that is not adversely affected by MSL disruption, male Drosophila cells (SL2). Finally, we measured absolute changes in expression of documented MSL target genes upon disruption of the complex by MSL2 RNAi. By isolating total nucleic acid and normalizing RNA signals to genomic DNA, decreases in $\mathrm{X}$-linked expression could be distinguished from increases in autosomal expression. Our results clearly reveal that compensation of the male Xchromosome is due to direct activation of genes by the MSL complex and furthermore demonstrate a local correlation between complex binding and hyperactivation of gene expression.

\section{Results and Discussion}

In order to study the wild-type binding pattern of MSL proteins to the male X chromosome, chromatin immunoprecipitations (ChIPs) with antibodies specific for MSL1, MOF and acetyl H4 Lys 16 were performed on Drosophila embryo chromatin. Precipitated DNA enriched in native binding sites for the MSL complex was amplified by ligation-mediated PCR and labeled for hybridization to a set of Southern blot membranes containing annotated restriction fragments representing 2.6 $\mathrm{Mb}$ of the distal tip of the $\mathrm{X}$ chromosome (G.D. Gilfillan and P.B. Becker, in prep.). MockChIP reactions from which the primary antibody was omitted provided values for normalization and calculation of enrichment factors. A subset of the results representing the interaction of the MSL complex across $170 \mathrm{~kb}$ of the chromosome is shown in Figure 1A. A broad peak of MSL protein binding and $\mathrm{H} 4$ acetylation can be seen over a gene cluster covering a region of $\sim 90 \mathrm{~kb}$. At least seven of the 29 illustrated genes are expressed at the embryonic developmental stage corresponding to the time when embryos were cross-linked for ChIP analysis (Arbeitman et al. 2002). To confirm the enrichments seen over this region, the

$\mathbf{B}$
ChIP hybridization results were verified by sequencespecific quantitative PCR (Q-PCR) at a location within the binding peak and two flanking regions of low binding
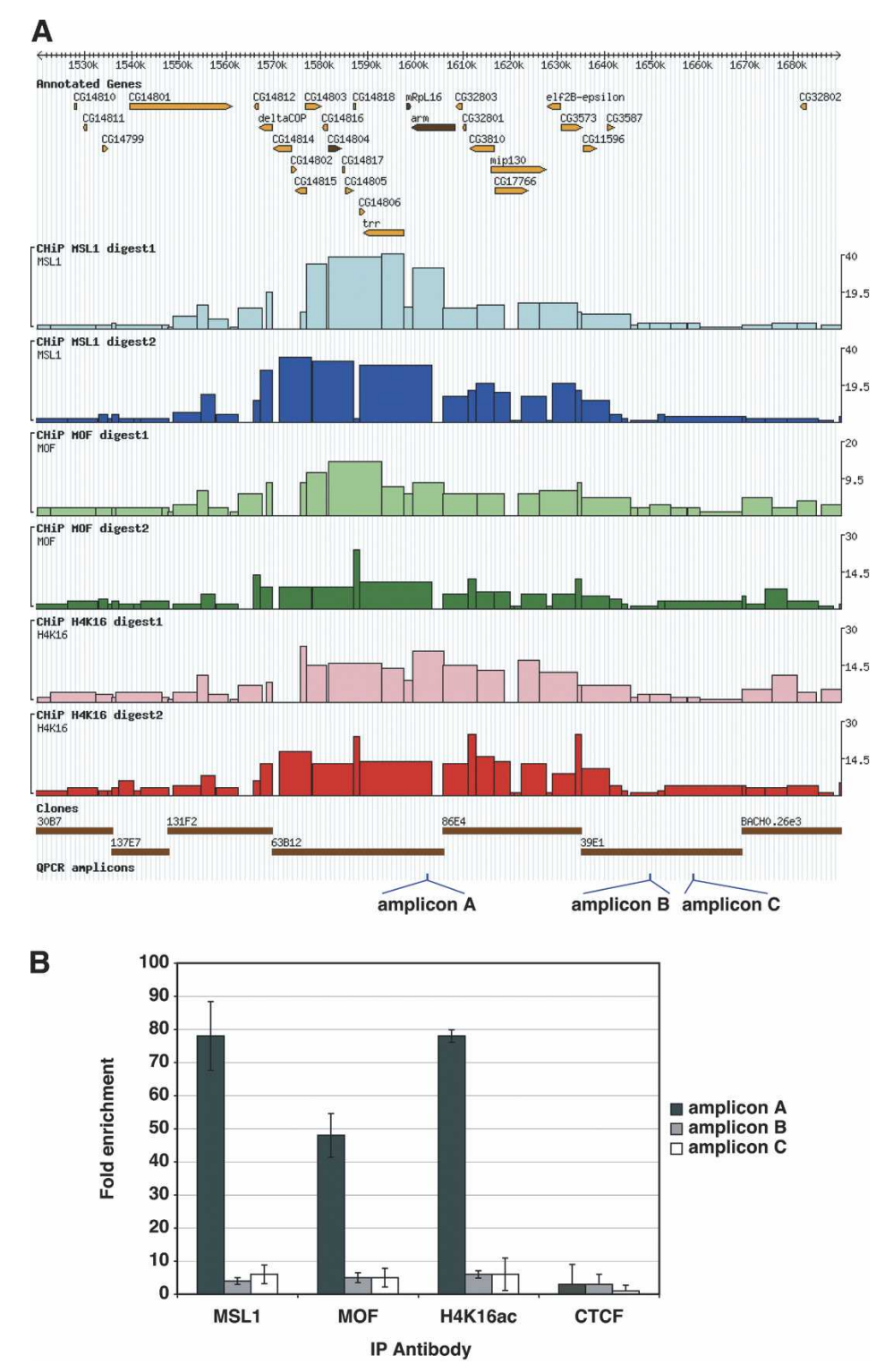

Figure 1. An MSL-binding region of the X chromosome in Drosophila embryos. (A) GBrowse genome browser (http://www.gmod.org) view of an X-chromosomal segment corresponding to region $1520-1690 \mathrm{~kb}$ on our tiling BAC chromosome walk (from position $1,667,917$ to $1,853,727$ in the gadfly rel.4.1.1 sequence of the $\mathrm{X}$ chromosome). Genes and coding strand orientations are indicated. Darkbrown-colored genes were subsequently subjected to expression analysis. ChIP data represents fold enrichment ( $Y$-axis) of specific IP over mock IP for the indicated antibodies, determined by quantitation of Southern blots. Blotted restriction fragments are represented by boxes, with length proportional to fragment size. Bands with low enrichments (less than three standard deviations above filter background levels) have been set to an enrichment of 1. Missing data points (for example clone ends of uncertain length) are represented by 0 on the scale. Note that all restriction fragments $<600 \mathrm{bp}$ in length are excluded from analysis and thus represent missing data points. For each clone, two restriction digests were performed, thus generating two data tracks per ChIP. Cosmid and $\mathrm{BAC}$ clones are indicated as an additional track. Q-PCR amplicons used to verify hybridization data are indicated at the bottom of the figure. The data shown represent a single hybridization experiment. $(B)$ Q-PCR performed with amplicons A, B, and C on immunoprecipitated chromatin from Drosophila embryos. Data indicate fold enrichment of specific IP over mock IP \pm standard deviation. 
(Fig. 1B). MSL binding was highly enriched in the middle of the domain and weak in the flanking regions. A control antibody not related to dosage compensation, raised against the insulator-binding protein CTCF (Moon et al. 2005) showed no significant binding at these positions. In addition, as an autosomal control, $\mathrm{P} 1$ and $\lambda$ phage clones covering the $340-\mathrm{kb}$ bithorax complex were included on the same Southern blots. On hybridization, the MSL1 and acetylated H4 ChIPs showed no enrichment at the bithorax complex, while MOF was seen to bind at a low level (average enrichment factor: 3) (data not shown). It is currently not clear whether the observed low-level binding of MOF to this autosomal sequence is of functional significance (MOF is also expressed in females and may hence have a function separate from other MSL proteins) (Hilfiker et al. 1997) or due to suboptimal data normalization.

The presence of the MSL proteins and acetylated H4K16 suggested that-according to the activation model-genes within this region are subject to dosage compensation in the male. In order to find out if disruption of complex affects gene expression from that locus, we moved our analysis to a cell system, which allows knockdown of the MSL complex by RNAi. Drosophila SL2 cells exhibit a male phenotype in that they are devoid of Sex-Lethal, express MSL2 (Bashaw and Baker 1995; Kelley et al. 1995; Zhou et al. 1995), and show specific enrichment of the MSL complex on the X chromosome. RNAi-mediated depletion of MSL proteins (Buscaino et al. 2003) results in loss of dosage compensation without affecting cell growth (Straub et al. 2005b). Knockdown of MSL2 leads to significant disruption of the complex from day 6 until day 12 after RNAi treatment (data not shown). We selected three genes from the region depicted in Figure 1A for study in SL2 cells. In line with our analysis performed in embryos, the genes CG14804, $m R p L 16$, and arm showed considerable MSL1 binding when assayed by ChIP (Fig. 2). In contrast, a fourth X-linked gene (CG14626) chosen from a more distal region that exhibited very low MSL binding in the embryo ChIP (data not shown) had binding barely above background levels.

We then addressed absolute changes in expression of these genes upon MSL2 knockdown using a novel experimental approach: By preparing total nucleic acids from

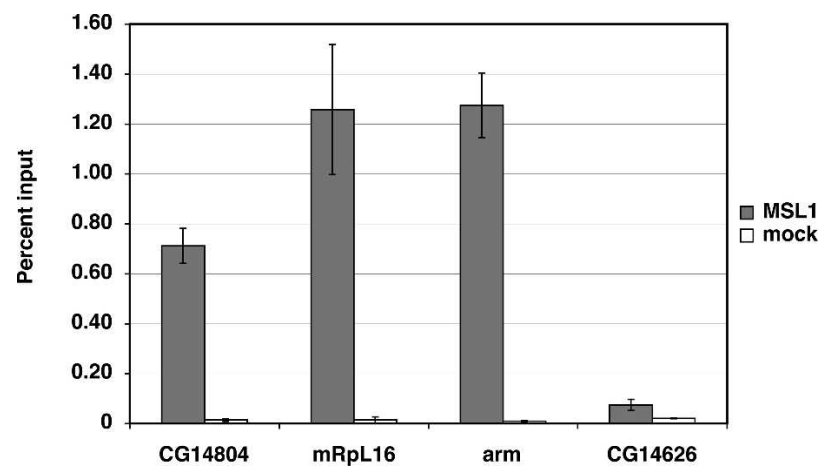

Figure 2. Genes on the X chromosome also bind MSL proteins in SL2 cells. ChIP was performed with anti-MSL1 antibody on chromatin from SL2 cells. A representative experiment from three independent ChIPs is shown. Amplicons for Q-PCR were designed within exon sequences of each gene. CG14804, $m R p L 16$ and arm are within the region depicted in Figure 1. CG14626 is from a region of low MSL binding in a more distal location on the X chromosome.
A

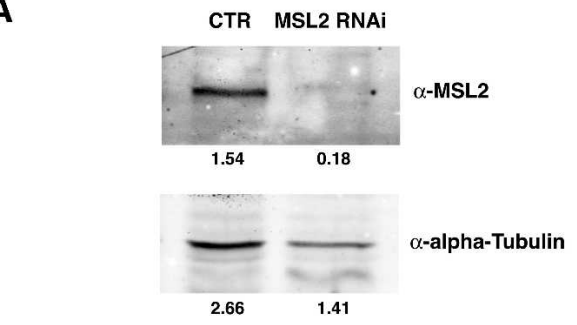

B

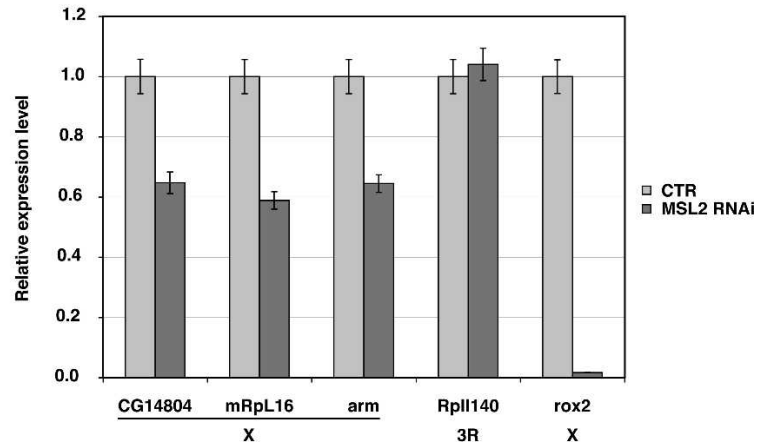

Figure 3. Depletion of MSL2 disrupts compensation of X-chromosomal gene expression. $(A$, top) MSL2 protein levels in control sample (GST RNAi) and cells treated with RNAi against MSL2. (Bottom) For normalization, the same Western blot membrane was probed with an $\alpha$-tubulin antibody. Numbers represent absolute band intensities after quantification of Western blot signals. (B) Change in gene expression of different target genes. Expression is displayed relative to the corresponding level in the control sample and represents the mean of three independent experiments ( \pm standard deviation).

SL2 cells under conditions that avoid distortion of the relative ratio of nucleic acids and using DNA- and RNAspecific primer pairs (Supplementary Fig. 1) we were able to quantify transcripts on a per-gene basis. Normalization of RNA-specific amplification in reference to DNAspecific signal allows direct comparison of control versus MSL2 RNAi-treated cells. According to the activation model, MSL complex disruption should result in an $\sim 50 \%$ decrease of expression of a fully compensated gene. According to the inverse model, however, transcript levels of X-linked genes should remain unaffected by MSL2 knockdown with autosomal expression being doubled. We achieved $\sim 80 \%$ target depletion as compared with control cells treated with double-stranded RNA (dsRNA) against GST 9-10 d after treatment of SL2 cells with anti-MSL2 dsRNA (Fig. 3A). When measuring transcript levels per gene in those cells by Q-PCR we obtained a clear-cut result (Fig. 3B): Expression of genes that are targets of MSL binding dropped in expression to $\sim 60 \%$ of wild-type expression (the differences in expression are clearly visible in the real-time amplification curves) (Supplementary Fig. 2). Given the incomplete target depletion, we expect expression to drop even lower, possibly close to $50 \%$, in total absence of MSL2. In contrast, roX2, an X-linked gene that is under direct control of MSL2 binding and not subjected to dosage compensation, dropped massively in expression. Transcript levels of the autosomally encoded RNA polymerase II subunit (RpII140), which has previously been subject to quantitative analysis in mutant embryos (Chiang and Kurnit 2003), did not change significantly upon MSL knockdown. 
In an independent study, Hamada et al. (2005) analyzed global gene expression upon disruption of the MSL complex in Drosophila SL2 cells. Based on statistical analyses, the authors also conclude that the majority of $\mathrm{X}$-linked genes are directly up-regulated by the MSL complex. The combined data support the model in which binding of the MSL complex to the male X chromosome serves to approximately double transcription of its target genes. In addition, our results demonstrate for the first time a direct relationship between MSL binding, histone hyperacetylation and tuning of gene expression at the level of individual genes. However, the MSL complex does not bind all the X-linked genes to the same extent (Fig. 1A). MSL binding may reflect the cell-typespecific gene expression pattern on the $\mathrm{X}$ chromosome (Sass et al. 2003). Accordingly, the level of binding might depend on the absolute rate of transcription of individual genes, which could point to a direct involvement of the complex in the transcription process. Furthermore, a number of genes have been proposed to be compensated by a post-transcriptional mechanism in females (Kelley et al. 1995) and therefore may not be targeted by the MSL complex. A graded level of binding might indicate different degrees of compensation and reflect more or less stringent requirements to overcome the haploinsufficiency of some genes. Chromosome-wide correlation of transcription levels, dosage compensation, and MSL binding will be required to solve the relevance of nonuniform complex distribution.

As regards the inverse model there is no evidence in our analysis for an inverse dosage effect being a substantial part of the compensation process of the male X chromosome. Even though such an effect appears to be an imperative response to spontaneous aneuploidies (Birchler et al. 2003, 2005), evolution of the compensation process of progressive X-chromosomal monosomy in Drosophila males (Bone and Kuroda 1996; Marin et al. 2000; Birchler et al. 2003) apparently favored a different mechanism. Conceivably, the progressive degeneration of the second $\mathrm{X}$ in Drosophila males was not rapid enough or did not involve segments large enough to trigger inverse dosage effects.

\section{Materials and methods}

Clones

Cosmid and BAC clones used by the European Drosophila Genome Project (Benos et al. 2000) were obtained from the participant laboratories or from the Human Genome Mapping Project (HGMP) resource center. The BAC clones (Benos et al. 2000) and cosmids clones (Siden-Kiamos et al. 1990) are available from http://www.geneservice.co.uk. Cosmid and BAC 96-well IDs and accession numbers are as follows: 30B7 (AL021107), 137E7 (AL021108), 131F2 (AL024456), 63B12 (AL021106), 86E4 (AL021086), 39E1 (AL009191), BACH0.26e3 (AL035245). Clones were grown in LB agar plus $25 \mu \mathrm{g} / \mathrm{ml}$ chloramphenicol (BACs) or $25 \mu \mathrm{g} / \mathrm{mL}$ kanamycin (cosmids). DNA was isolated using Qiagen maxi-prep kits.

Southern transfer and hybridization

BAC and cosmid clones were digested with two restriction enzymes, selected to yield a nonoverlapping digestion pattern. Selected digests were as follows (clone name, digest 1, digest2): 30B7, AflII, SphI; 137E7, Alw44I, AflII; 131F2, PvuII, Alw44I; 63B12, BamHI, HindIII; 86E4, Asp700I, ClaI; 39E1, HindIII, EcoRI; BACH0.26e3, BglI, EcoRV. Approximately $1 \mu \mathrm{g}$ cosmid and $2 \mu \mathrm{g}$ BAC DNA was loaded per lane on $0.8 \%$ agarose gels. Loading was equalized to allow for differences in insert size by normalizing to a restriction fragment common to vector backbone. Electrophoresis was performed at $6 \mathrm{~V} / \mathrm{cm}$ in TAE buffer supplemented with $0.5 \mu \mathrm{g} / \mathrm{mL}$ ethidium bromide, until fragments $<0.5 \mathrm{~kb}$ in size were lost from the anode end of the gel. Gels were then sequentially soaked in depurination buffer $(0.2 \mathrm{M} \mathrm{HCl})$ for $15 \mathrm{~min}$, in denaturation buffer (1.5 M $\mathrm{NaCl}, 0.5 \mathrm{M} \mathrm{NaOH})$ for $20 \mathrm{~min}$, and in neutralization buffer $(1.5 \mathrm{M} \mathrm{NaCl}$, $1 \mathrm{M}$ Tris- $\mathrm{HCl}$ at $\mathrm{pH} \mathrm{7.5)} \mathrm{for} 20 \mathrm{~min}$. Southern transfer to Genescreen nylon membrane (PerkinElmer Life Sciences) was performed by capilliary transfer in $20 \times \mathrm{SSC}(3.3 \mathrm{M} \mathrm{NaCl}, 0.3 \mathrm{M} \mathrm{Na}$-citrate). DNA was crosslinked to membranes by baking for $2 \mathrm{~h}$ at $80^{\circ} \mathrm{C}$. Southern hybridization was performed as described (Church and Gilbert 1984).

ChIP

ChIPs were performed on chromatin prepared from Drosophila SL2 cells and from 12-14-h-old mixed-sex embryos. The MSL complex is not present in female embryos, so females are expected to contribute only background level signals in the ChIPs. ChIP from embryos and SL2 cells was performed as described previously, including purification over a $\mathrm{CsCl}$ gradient (Kageyama et al. 2001). In addition, chromatin was also purified from both cells and embryos using a CsCl-free protocol (Schwartz et al. 2005). Similar results were obtained from both protocols for all Q-PCR amplicons tested in this analysis. Embryos (12-14 h after egg laying) were fixed in $4 \%$ formaldehyde for 15 min at $18^{\circ} \mathrm{C}$; SL2 cells were fixed in $1 \%$ formaldehyde for $1 \mathrm{~h}$ at $4^{\circ} \mathrm{C}$. Antibodies against MSL1 $(2 \mu \mathrm{L} / \mathrm{IP})$ and MOF $(5 \mu \mathrm{L} / \mathrm{IP})$ were gifts from M. Kuroda (Harvard Medical School, Boston, MA). Anti-CTCF (16 $\mu \mathrm{L} / \mathrm{IP})$ was a gift from R. Renkawitz (Justus LiebigUniversity, Giessen, Germany). Antibodies against acetyl H4 Lys 16 AHP417 (3 $\mu \mathrm{L} / \mathrm{IP})$ and control rabbit IgG antibodies SC2027 (5 $\mu \mathrm{L} / \mathrm{IP})$ were purchased from Serotec and Santa Cruz Biotech, respectively. Following immunoprecipitation (IP) and reversal of cross-links, recovered DNA was resuspended in a final volume of $22 \mu \mathrm{L} \mathrm{H}_{2} \mathrm{O}$. Seven microliters of this DNA was incubated with Pfu polymerase, ligated to linker and subject to linker-mediated PCR prior to random priming for use as a probe in Southern hybridization. Following hybridization, signals from individual bands were quantitated using a Fuji FLA-3000 PhosphorImager. Low-intensity hybridization signals (less than three standard deviations above filter background) in the specific IP were discarded and assigned an arbitrary enrichment value of 1 . Dividing the values from the specific MSL ChIP by those of the mock IP allowed calculation of foldenrichment. Alternatively, $0.1 \mu \mathrm{L}$ of immunoprecipitated DNA was used without further modification as template for Q-PCR analysis.

Q-PCR

Q-PCR was carried out using the ABI PRISM 7000 Sequence detection system (Applied Biosystems). SYBR Green 2× PCR Master Mix (Applied Biosystems) was used according to the manufacturer's directions. For amplicons A, B, and C, the nonstandard annealing temperature of $65^{\circ} \mathrm{C}$ was used. For all others, the recommended standard temperature of $60^{\circ} \mathrm{C}$ was used.

RNAi knockdown of MSL2

dsRNA was produced and Drosophila SL2 cells were treated according to published procedures (Maiato et al. 2003). In brief, $1.5 \times 10^{6}$ SL2 cells were incubated with $10 \mu \mathrm{g}$ dsRNA for $1 \mathrm{~h}$ in serum-free medium. After addition of serum-containing medium, cells were incubated 9-10 d (including one passage) at $26^{\circ} \mathrm{C}$ before analysis.

Western blot analysis

Cells were extracted in $50 \mathrm{mM}$ Tris- $\mathrm{HCl}$ (pH 7.5), $150 \mathrm{mM} \mathrm{NaCl}, 1 \%$ NP-40, 0.5\% deoxycholate, $0.1 \%$ SDS, 0.4 mM EDTA, 10\% glycerol. Extract containing $10 \mu \mathrm{g}$ of total protein was separated by SDS-PAGE, transferred onto polyvinylidene fluoride (PVDF) membranes, probed with the indicated antibodies, detected with fluorescently labeled secondary antibodies and quantified with an Odyssey system (Li-Cor).

Measurement of absolute changes in gene expression Simultaneous preparation of DNA and RNA was performed according to Merante et al. (1996). In brief, $25 \times 10^{6}$ SL2 cells were thoroughly extracted by addition of $4 \mathrm{~mL}$ phenol equilibrated with STEL $(0.2 \%$ SDS, 10 $\mathrm{mM}$ Tris- $\mathrm{HCl}$ at $\mathrm{pH}$ 7.5, $10 \mathrm{mM}$ EDTA, $100 \mathrm{mM} \mathrm{LiCl}$ ) and $4 \mathrm{~mL}$ STEL buffer. After centrifugation, the aqueous phase was re-extracted twice using STEL-Phenol-Chloroform. Nucleic acids were precipitated by addition of 0.1 volume of $5 \mathrm{M} \mathrm{LiCl}$ and 2 volumes of ethanol. After intense washing with $70 \%$ ethanol the pellet was dried and dissolved in $100 \mu \mathrm{L}$ RNase-free water. Two micrograms of nucleic acids were reverse transcribed in a $20-\mu \mathrm{L}$ reaction using random hexamer primers and SuperScriptII Reverse Transcriptase (Invitrogen) according to the manufacturer's recommendations. Five microliters of a 30-fold dilution of the $\mathrm{RT}$ reaction was analyzed per real-time PCR under conditions described above. For each experiment, four replicates of each sample (MSL2 RNAi) 
and control (GST RNAi) were analyzed in parallel. Absolute changes in gene expression were obtained by normalizing the amount of transcripts to genomic DNA present in the samples. Both an X-chromosomal and an autosomal DNA amplicon were analyzed to confirm the validity of genomic DNA amplification. Data analysis based on the $2^{-\Delta \Delta C T}$ method (Livak and Schmittgen 2001) was performed using the Relative Quantification module of the Sequence Detection System software (Applied Biosystems).

\section{Acknowledgments}

We are grateful to M. Kuroda and colleagues for sharing results prior to publication and for providing antibodies against MSL1 and MOF. We thank R. Renkawitz for the anti-CTCF antibody, R. Lamm for technical assistance, and members of the laboratory for helpful discussion. This work was supported by grants to P.B.B. from Deutsche Forschungsgemeinschaft (Transregio5, TPA1) and the German Ministry for Education and Research, Verbundprojekt 0313030 B.

\section{References}

Akhtar, A. and Becker, P.B. 2000. Activation of transcription through histone $\mathrm{H} 4$ acetylation by MOF, an acetyltransferase essential for dosage compensation in Drosophila. Mol. Cell 5: 367-375.

Arbeitman, M.N., Furlong, E.E., Imam, F., Johnson, E., Null, B.H., Baker, B.S., Krasnow, M.A., Scott, M.P., Davis, R.W., and White, K.P. 2002. Gene expression during the life cycle of Drosophila melanogaster. Science 297: 2270-2275.

Bashaw, G.J. and Baker, B.S. 1995. The msl-2 dosage compensation gene of Drosophila encodes a putative DNA-binding protein whose expression is sex specifically regulated by Sex-lethal. Development 121: 3245-3258.

Belote, J.M. and Lucchesi, J.C. 1980. Control of X chromosome transcription by the maleless gene in Drosophila. Nature 285: 573-575.

Benos, P.V., Gatt, M.K., Ashburner, M., Murphy, L., Harris, D., Barrell, B., Ferraz, C., Vidal, S., Brun, C., Demailles, J., et al. 2000. From sequence to chromosome: The tip of the X chromosome of D. melanogaster. Science 287: 2220-2222.

Bhadra, U., Pal-Bhadra, M., and Birchler, J.A. 1999. Role of the male specific lethal (msl) genes in modifying the effects of sex chromosomal dosage in Drosophila. Genetics 152: 249-268.

- 2000. Histone acetylation and gene expression analysis of sex lethal mutants in Drosophila. Genetics 155: 753-763.

Birchler, J.A., Bhadra, U., Bhadra, M.P., and Auger, D.L. 2001. Dosagedependent gene regulation in multicellular eukaryotes: Implications for dosage compensation, aneuploid syndromes, and quantitative traits. Dev. Biol. 234: 275-288.

Birchler, J.A., Pal-Bhadra, M., and Bhadra, U. 2003. Dosage dependent gene regulation and the compensation of the $\mathrm{X}$ chromosome in Drosophila males. Genetica 117: 179-190.

Birchler, J.A., Riddle, N.C., Auger, D.L., and Veitia, R.A. 2005. Dosage balance in gene regulation: Biological implications. Trends Genet. 21: 219-226.

Bone, J.R. and Kuroda, M.I. 1996. Dosage compensation regulatory proteins and the evolution of sex chromosomes in Drosophila. Genetics 144: 705-713.

Buscaino, A., Kocher, T., Kind, J.H., Holz, H., Taipale, M., Wagner, K., Wilm, M., and Akhtar, A. 2003. MOF-regulated acetylation of MSL-3 in the Drosophila dosage compensation complex. Mol. Cell 11: 1265-1277.

Chiang, P.W. and Kurnit, D.M. 2003. Study of dosage compensation in Drosophila. Genetics 165: 1167-1181.

Church, G.M. and Gilbert, W. 1984. Genomic sequencing. Proc. Natl. Acad. Sci. 81: 1991-1995.

Demakova, O.V., Kotlikova, I.V., Gordadze, P.R., Alekseyenko, A.A., Kuroda, M.I., and Zhimulev, I.F. 2003. The MSL complex levels are critical for its correct targeting to the chromosomes in Drosophila melanogaster. Chromosoma 112: 103-115.

Franke, A. and Baker, B.S. 1999. The rox1 and rox2 RNAs are essential components of the compensasome, which mediates dosage compensation in Drosophila. Mol. Cell 4: 117-122.

Gorman, M. and Baker, B.S. 1994. How flies make one equal two: Dosage compensation in Drosophila. Trends Genet. 10: 376-380.

Gorman, M., Franke, A., and Baker, B.S. 1995. Molecular characterization of the male-specific lethal-3 gene and investigations of the regulation of dosage compensation in Drosophila. Development 121: 463-475.
Gu, W., Szauter, P., and Lucchesi, J.C. 1998. Targeting of MOF, a putative histone acetyl transferase, to the $\mathrm{X}$ chromosome of Drosophila melanogaster. Dev. Genet. 22: 56-64.

Hamada, F.N., Park, P.J., Gordadze, P.R., and Kuroda, M.I. Global regulation of X-chromosomal genes by the MSL complex in Drosophila melanogaster. Genes \& Dev. (this issue).

Hiebert, J.C. and Birchler, J.A. 1994. Effects of the maleless mutation on $\mathrm{X}$ and autosomal gene expression in Drosophila melanogaster. Genetics 136: 913-926.

Hilfiker, A., Hilfiker-Kleiner, D., Pannuti, A., and Lucchesi, J.C. 1997. mof, a putative acetyl transferase gene related to the Tip60 and MOZ human genes and to the SAS genes of yeast, is required for dosage compensation in Drosophila. EMBO J. 16: 2054-2060.

Kageyama, Y., Mengus, G., Gilfillan, G., Kennedy, H.G., Stuckenholz, C., Kelley, R.L., Becker, P.B., and Kuroda, M.I. 2001. Association and spreading of the Drosophila dosage compensation complex from a discrete roX1 chromatin entry site. EMBO J. 20: 2236-2245.

Kelley, R.L. and Kuroda, M.I. 1995. Equality for X chromosomes. Science 270: $1607-1610$.

Kelley, R.L., Solovyeva, I., Lyman, L.M., Richman, R., Solovyev, V., and Kuroda, M.I. 1995. Expression of msl-2 causes assembly of dosage compensation regulators on the $\mathrm{X}$ chromosomes and female lethality in Drosophila. Cell 81: 867-877.

Kuroda, M.I., Kernan, M.J., Kreber, R., Ganetzky, B., and Baker, B.S. 1991. The maleless protein associates with the $\mathrm{X}$ chromosome to regulate dosage compensation in Drosophila. Cell 66: 935-947.

Livak, K.J. and Schmittgen, T.D. 2001. Analysis of relative gene expression data using real-time quantitative PCR and the $2^{-\Delta \Delta C(T)}$ method. Methods 25: 402-408.

Lucchesi, J.C. 1998. Dosage compensation in flies and worms: The ups and downs of X-chromosome regulation. Curr. Opin. Genet. Dev. 8: $179-184$.

Maiato, H., Sunkel, C.E., and Earnshaw, W.C. 2003. Dissecting mitosis by RNAi in Drosophila tissue culture cells. Biol. Proced. Online 5: 153-161.

Marin, I., Siegal, M.L., and Baker, B.S. 2000. The evolution of dosagecompensation mechanisms. Bioessays 22: 1106-1114.

Merante, F., Raha, S., Reed, J.K., and Proteau, G. 1996. The simultaneous isolation of RNA and DNA from tissues and cultured cells. Methods Mol. Biol. 58: 3-9.

Moon, H., Filippova, G., Loukinov, D., Pugacheva, E., Chen, Q., Smith, S.T., Munhall, A., Grewe, B., Bartkuhn, M., Arnold, R., et al. 2005. CTCF is conserved from Drosophila to humans and confers enhancer blocking of the Fab-8 insulator. EMBO Rep. 6: 165-170.

Pal Bhadra, M., Bhadra, U., Kundu, J., and Birchler, J.A. 2005. Gene expression analysis of the function of the MSL complex in Drosophila. Genetics 169: 2061-2074.

Palmer, M.J., Mergner, V.A., Richman, R., Manning, J.E., Kuroda, M.I., and Lucchesi, J.C. 1993. The male-specific lethal-one (msl-1) gene of Drosophila melanogaster encodes a novel protein that associates with the X chromosome in males. Genetics 134: 545-557.

Sass, G.L., Pannuti, A., and Lucchesi, J.C. 2003. Male-specific lethal complex of Drosophila targets activated regions of the X chromosome for chromatin remodeling. Proc. Natl. Acad. Sci. USA 100: 8287-8291.

Schwartz, Y.B., Kahn, T.G., and Pirrotta, V. 2005. Characteristic low density and shear sensitivity of cross-linked chromatin containing polycomb complexes. Mol. Cell. Biol. 25: 432-439.

Siden-Kiamos, I., Saunders, R.D., Spanos, L., Majerus, T., Treanear, J., Savakis, C., Louis, C., Glover, D.M., Ashburner, M., and Kafatos, F.C. 1990. Towards a physical map of the Drosophila melanogaster genome: Mapping of cosmid clones within defined genomic divisions. Nucleic Acids Res. 18: 6261-6270.

Straub, T., Dahlsveen, I.K., and Becker, P.B. 2005a. Dosage compensation in flies: Mechanism, models, mystery. FEBS Lett. 579: 3258-3263.

Straub, T., Neumann, M.F., Prestel, M., Kremmer, E., Kaether, C., Haas, C., and Becker, P.B. 2005b. Stable chromosomal association of MSL2 defines a dosage compensated nuclear compartment. Chromosoma (in press).

Zhou, S., Yang, Y., Scott, M.J., Pannuti, A., Fehr, K.C., Eisen, A., Koonin, E.V., Fouts, D.L., Wrightsman, R., Manning, J.E., et al. 1995. Malespecific lethal 2, a dosage compensation gene of Drosophila, undergoes sex-specific regulation and encodes a protein with a RING finger and a metallothionein-like cysteine cluster. $E M B O J$. 14: 2884-2895. 


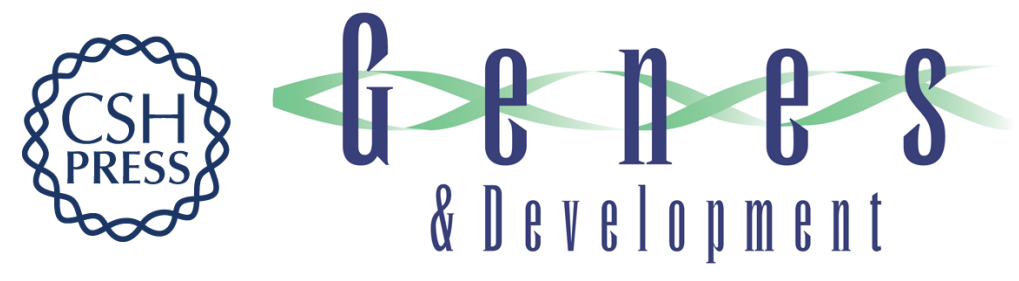

\section{The Drosophila MSL complex activates the transcription of target genes}

Tobias Straub, Gregor D. Gilfillan, Verena K. Maier, et al.

Genes Dev. 2005, 19:

Access the most recent version at doi:10.1101/gad.1343105

\section{Supplemental http://genesdev.cshlp.org/content/suppl/2005/09/19/19.19.2284.DC1 Material}

References This article cites 38 articles, 17 of which can be accessed free at: http://genesdev.cshlp.org/content/19/19/2284.full.html\#ref-list-1

\section{License}

Email Alerting

Receive free email alerts when new articles cite this article - sign up in the box at the top Service

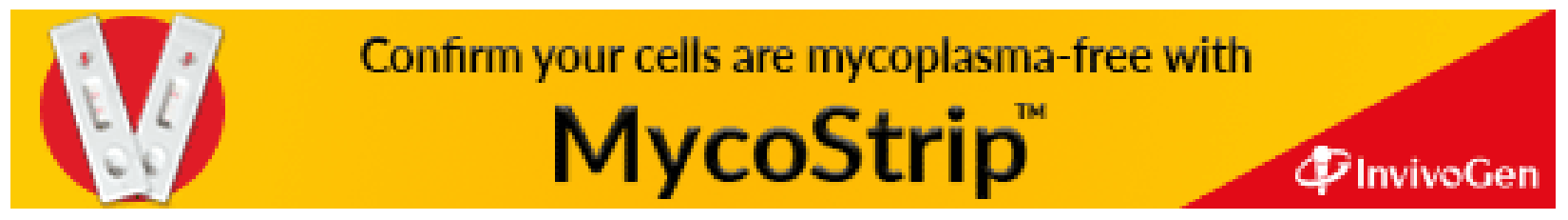

